\title{
Vascularisation of Urethral Repairs with the Gracilis Muscle Flap
}

\author{
Ee Hsiang Jonah Kua, Kah Woon Leo, Yee Siang Ong, Christopher Cheng, Bien-Keem Tan \\ Department of Plastic, Reconstructive and Aesthetic Surgery, Singapore General Hospital, Singapore
}

Background The ability to achieve a long-term, stricture-free urethral repair is one of the ongoing challenges of reconstructive urologic surgery. A successful initial repair is critical, as repeat procedures are difficult, owing to distortion, scarring, and short urethral stumps.

Methods We describe a technique in which the gracilis muscle flap is laid on or wrapped around the urethral repair site to provide a well-vascularised soft tissue reinforcement for urethral repair. This technique promotes vascular induction, whereby a new blood supply is introduced to the repair site to improve the outcome of urethral repair or anastomotic urethroplasty. The surface contact between the muscle flap and the repair site is enhanced by the use of fibrin glue to improve adherence and promote inosculation and healing. We employed this technique in 4 patients with different urethral defects.

Results After a follow-up period of 32 to 108 months, all of the urethral repairs were successful without complications.

Conclusions Our results suggest that the use of a gracilis muscle flap to vascularise urethral repairs can improve the outcome of challenging urethral repairs.

Keywords Urethra / Surgical flaps / Muscles
Correspondence: Bien-Keem Tan Department of Plastic, Reconstructive and Aesthetic Surgery, Singapore General Hospital, Outram Road, Singapore 169608

Tel: $+65-6321-4686$

Fax: +65-6225-9340

E-mail: bienkeem@gmail.com

Received: 3 Jun 2013 • Revised: 20 Aug 2013 • Accepted: 22 Aug 2013

pISSN: 2234-6163・ elSSN: 2234-6171 • http://dx.doi.org/10.5999/aps.2013.40.5.584• Arch Plast Surg 2013;40:584-588

\section{INTRODUCTION}

One of the ongoing challenges in urologic surgery is achieving a stricture-free urethral repair. Many patients suffer from recurrent strictures and urinary fistulas, which is distressing because of an inability to void normally, infection, and urinary leakage. The incidence of stenosis, fistula, and diverticula formation have been reported to be $7 \%$ to $68 \%$ [1]. A successful initial repair is critical, as repeat procedures are difficult owing to distortion, scarring, and short urethral stumps. The current approach to primary urethral repair includes anastomotic urethroplasty (endto-end repair) for short defects and substitution (patch or interpositional) urethroplasty with grafts or flaps for long defects. No single technique is complication-free. We postulate that isch- emia at the repair site is a causative factor not well highlighted in the literature and it could result from trauma, infection, and tissue mobilisation during surgery. Over the years, many animal studies have shown that muscle flaps are able to introduce vascularity to ischemic tissue beds by angiogenesis. The purpose of this paper is to describe how we use a gracilis muscle flap to augment the blood supply at urethral repair sites.

\section{METHODS}

Between February 2002 and June 2010, 4 patients underwent urethral repair for defects that had resulted from surgical excision of testicular teratoma $(\mathrm{n}=1)$, advanced rectal carcinoma $(n=2)$, and Fournier's gangrene $(n=1)$. Their mean age was 
50 years (range, 27-76 years). Surgery was performed with the urologist who repaired the urethral defects using methods including: direct longitudinal repair $(\mathrm{n}=2)$, penile skin flap $(n=1)$, and end-to-end urethral anastomosis $(n=1)$. The location of the defects were the penile-bulbar junction $(n=1)$, bulbar urethra $(\mathrm{n}=1)$ and prostatic urethra $(\mathrm{n}=2)$ (Table 1$)$. In the anastomotic urethroplasty technique, the urethral ends were spatulated to increase the luminal diameter and mobilised to minimise tension at the repair site. Our role after the urethral repair was to introduce well-vascularised tissue by way of a muscle flap to reinforce the repair site.

The gracilis muscle flap was chosen because of its proximity. It was harvested using the standard technique with the patient in the lithotomy position. With the hip abducted and knee extended, the gracilis was identified as a taut slender muscle apart from the adductors. A 6-cm incision was made over the proximal gracilis and deepened to expose the muscle. The pedicle was identified in the septum between the gracilis and adductor longus (this is typically $10 \mathrm{~cm}$ distal to the pubic tubercle.) A $1-\mathrm{cm}$ incision was made at the medial aspect of the knee to release its tendon. The muscle was freed circumferentially by finger dissection, taking care to identify and ligate the secondary pedicle. Having been fully mobilised, the gracilis was carefully delivered through a subcutaneous tunnel into the perineum without twisting the pedicle. For improved reach, the hips were adducted by closing in the stirrups. The gracilis was used as an onlay over longitudinal repairs and as a "wrap-around" over anastomotic repairs. It was secured to the surrounding tissues with Vicryl 3-0 sutures after $2 \mathrm{~mL}$ of fast-acting fibrin glue (Tisseel, Baxter Healthcare, Illinois, United States) was applied between the flap and the urethra repair site. An indwelling Foley catheter was used to protect the repair for 2 to 4 weeks until a micturating cystourethrogram (MCU) showed complete healing.

\section{RESULTS}

The follow-up period was 32 to 108 months. There were no donor site complications. All of the urethral repairs were patent

\section{Table 1. Summary of patients}

\begin{tabular}{|lcllll|}
\hline Patient & Age $(\mathbf{y r})$ & \multicolumn{1}{c}{ Diagnosis } & Urethral defect $(\mathbf{c m}) /$ Site & Method of urethral repair & $\begin{array}{c}\text { Technique of gracilis } \\
\text { flap application }\end{array}$ \\
\hline 1 & 28 & Mixed germ cell testicular tumour & 1/Bulbar urethra & Direct longitudinal repair & Onlay \\
2 & 64 & Stage llc rectal carcinoma & 4/Prostatic urethra & Anastomotic urethroplasty & Wrap-around \\
3 & 33 & Fournier's gangrene & 3/Penile and bulbar urethra & Penile skin flap urethroplasty & Onlay \\
4 & 76 & Recurrent rectal carcinoma & 1/Prostatic urethra & Direct longitudinal repair & Onlay \\
\hline
\end{tabular}

\section{Fig. 1. Gracilis flap as an onlay}

(A) A 28-year-old man with mixed germ cell tumour of the right testis. (B, C, D) After wide resection of the tumour and direct repair of the bulbar urethral defect, a pedicled gracilis muscle flap was raised and applied to the repair. (E) Micturating cystourethrogram showing smooth passage of urine and absence of stricture or leak. (F) Six months postoperatively, the patient was able to micturate with a good stream.
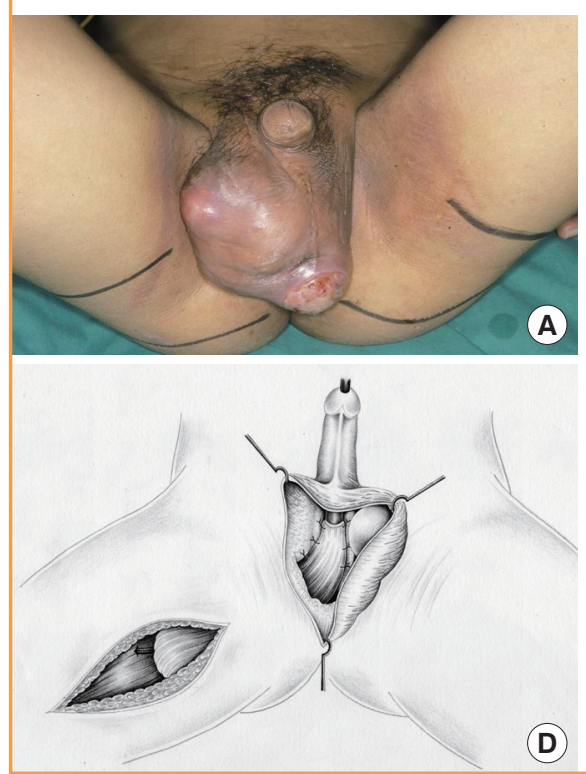
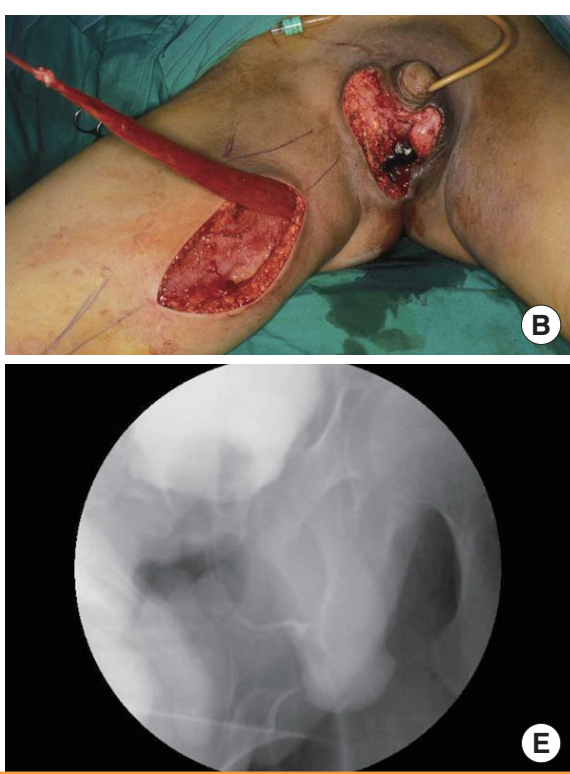

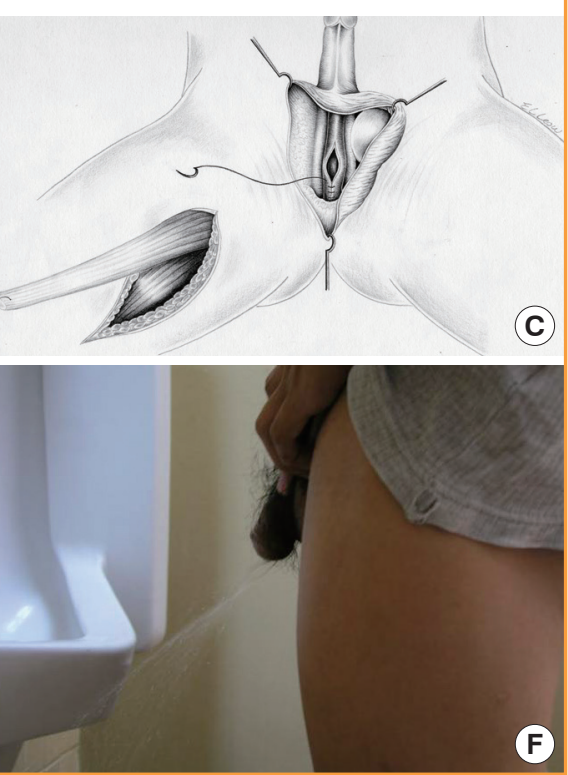


with no recurrence of fistula as evidenced by the postoperative MCUs. One of the patients was incontinent, as the urethral defect involved a large segment of the membranous and prostatic urethra.

\section{Case 1}

A 28-year-old man presented with a recurrent right mixed germ cell testicular tumour that had extended across the midline and through the tunica albuginea, ulcerating through the left scrotal skin (Fig. 1A). The tumour involved the corpus spongiosum and was deeply adherent to the urethra. Oncologic resection resulted in a 1-cm defect over the ventral wall of the bulbar urethra. The defect was repaired over a Foley catheter with a single layer of Polydioxanone 5/0 (PDS). The urethral anastomotic site was exposed with minimal surrounding local tissue for a layered perineal closure. A pedicled gracilis muscle flap was used as an onlay to vascularise the repair site. The remnant scrotal skin was mobilised, and the skin defect could be closed primarily (Fig. 1B-D). An MCU performed 3 months postoperatively showed smooth passage of urine and absence of stricture or leak (Fig. 1E). He recovered well and was able to micturate with a good stream (Fig. 1F).

\section{Case 2}

A 64-year-old man presented with a stage IIc rectal carcinoma. He underwent an abdominoperineal resection which included part of the posterior wall of the prostatic urethra as the tumour was adherent to it. The defect was repaired and despite suprapubic urinary diversion, a urethrocutaneous fistula developed 1 month later. Repeat surgery showed a small prostate remnant with a $3 \mathrm{~cm}$ prostatic urethral defect. The prostate remnant with its urethral segment were resected to the bladder neck (Fig. 2A). The bulbar urethra was then mobilised and anastomosed directly to the bladder neck. There was an absence of soft tissue posterior to the anastomosis due to the previous abdominoperineal resection. A gracilis muscle was wrapped around the anastomosis to buttress and support it (Fig. 2B-D). In addition, a gluteus maximus muscle flap was transposed into the pelvic cavity to obliterate the dead space. He had an uncomplicated recovery and the MCU showed smooth passage of urine with no stricture or leak after 3 months (Fig. 2E). However, he was incontinent and had to wear diapers.

\section{Case 3}

A 33-year-old man with type I diabetes mellitus presented with Fournier's gangrene. Debridement of the necrotic bulbar urethra resulted in a long ventral urethral defect extending from the distal penile urethra to $2 \mathrm{~cm}$ distal to the verumontanum. The urethral plate was intact and a penile skin flap urethroplasty was performed. A transverse segment of prepuce was harvested. It was pedicled on the superficial layer of the Buck's fascia. The skin and pedicle were divided ventrally, and the skin island was rotated and sutured to the urethral defect as a ventral onlay. Although there was sufficient skin coverage from local advance-

\section{Fig. 2. Reinforcing the urethral defect circumferentially}

(A) A 64-year-old man with rectal carcinoma invading the prostate had a $4-\mathrm{cm}$ urethral defect after resection. (B, C, D) The distal end of the urethra was anastomosed to the bladder neck and the gracilis flap was wrapped around the repair. (E) Micturating cystourethrogram showing a patent urethra with no leak.

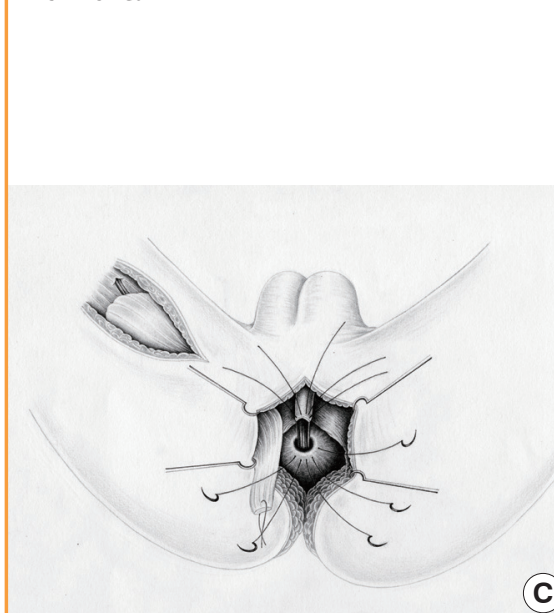

(C)
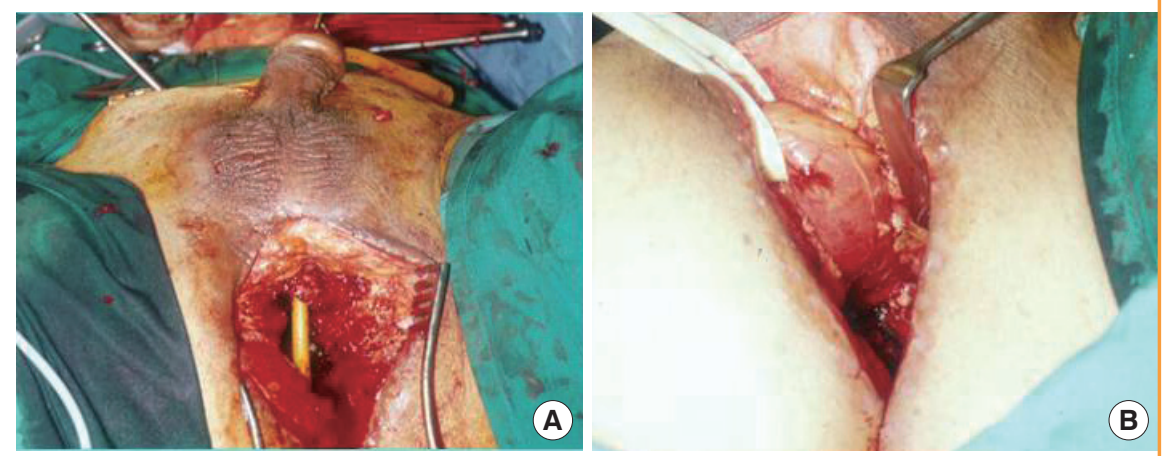

B) 
ment, a right gracilis muscle was used as an onlay to reinforce the urethroplasty site. MCU performed 6 months postoperatively showed that the urethra was patent with no contrast leakage or stricture. He was followed up for 9 years.

\section{Case 4}

A 76-year-old man had a previous radical prostatectomy and ultra-low anterior resection for prostatic and rectal carcinoma. He developed tumour recurrence at the puborectalis with involvement of the posterior wall of the bladder. Further perineal dissection with wide margins resulted in a small defect at the previous urethral-bladder neck junction. This was repaired primarily but complicated by a urethrocutaneous fistula with recurrent urinary leak. The fistula was excised, and the urethral defect was repaired primarily. A pedicled gracilis flap was raised as an onlay over the suture line. The wound was closed primarily after local advancement of the surrounding tissue. The perineal wound healed well, and there was no contrast leak on the MCU performed 3 months postoperatively.

\section{DISCUSSION}

The urethra is relatively well-vascularised with a unique dual blood supply [2]. Proximally, it is supplied in an antegrade manner by the bulbar and circumflex cavernosal arteries. Distally, in a retrograde manner by arborisations of the dorsal penile artery. Therefore, the distal and proximal ends of the urethra are supplied by separate arteries, allowing the urethra to be transected and anastomosed successfully. However, the retrograde blood flow to the distal segment can still be compromised when the urethra is mobilized extensively, resulting in ischemia at the repair site. We believe that ischemia at the urethral repair site is the cause of stricture and fistula formation. Clinical studies have shown that pelvic fractures with vascular injuries were associated with higher rates of failed urethral repairs [3]. It is also observed that in patients with traumatic pudendal vessel disruption, penile revascularisation led to improved patency rates after urethral repair [4].

Muscle flaps are effective vascularising agents. They have been shown to induce neo-vascularisation in an ischemic recipient bed, enhance white cell function in chronically fibrotic wounds, and promote healing of infected wounds $[5,6]$. Limbs with arterial occlusive disease and ischemic myocardium have been successfully revascularised by muscle flaps $[7,8]$. Experimentally, bone chips, allogenic trachea, and pancreatic tissue wrapped in skeletal muscles have been used as vascularised grafts [9]. Histological analysis in these experiments revealed that new microvascular connections developed between the muscle flap and the recipient bed $[7,8]$. Electron microscopic studies showed that skeletal muscles have a dense capillary network of 2,000 capillaries $/ \mathrm{mm}^{2}$ and a high resting blood flow, which is 4 times that of skin [10]. We believe that this property aids in the delivery of growth factors that promote wound healing and angiogenesis [11].

With extensive tissue mobilisation, the urethral edges at the suture line become relatively ischemic. Our technique aims to promote neo-vascularisation at the repair site to prevent ischemic fibrosis. To maximize contact between the muscle and the suture line, the gracilis muscle was used as an onlay over longitudinal repairs and wrapped circumferentially for anastomotic repairs. This directed neo-vascularisation specifically to the repair site. The gracilis was chosen because it is an effective and versatile pedicled muscle flap for urogenital reconstruction. It has reliable vascularity, can be harvested with relative ease, and can be mobilised to the perineum without tension or significant donor site morbidity. Therefore, it has been used successfully in covering perineal defects and treating urethral, rectourethral, and rectovaginal fistulas $[12,13]$. The gracilis has been used for urethral reconstruction in various ways. It can be transposed to cover a buccal mucosal graft and anchored to the periurethral tissues, obliterating dead space and providing vascular support to the graft $[14,15]$. Alternatively, a myocutaneous gracilis flap can be tubed and used to substitute long segments of urethral defect $[14,15]$. A neourethra can also be created from a combined prefabricated skin and muscle flap [16]. The gracilis has also been described as a vascularised cover for a 'fragile and unsupported' neourethra that is reconstructed using local flaps [17-19]. This is the first time that the gracilis has been reported to be specifically used as a vascularising agent for anastomotic urethroplasties and longitudinal repairs. We believe that this is indicated when the urethra has been mobilised and skeletonised after extensive perineal debridement or oncological resection. Besides its role in vascular induction, the gracilis also provides vital structural support for the urethral anastomosis. In situations where there is extensive dead space around the urethral repair site, an additional muscle flap (i.e., gluteus muscle flap or contralateral gracilis) is required.

In conclusion, recurrent urethral strictures and urinary fistulas are debilitating conditions. A successful initial repair is critical, as repeat procedures are increasingly difficult. Our results suggest that the use of a gracilis muscle flap to vascularise urethral repairs can improve the outcome of challenging urethral repairs.

\section{REFERENCES}

1. Andrich DE, Dunglison N, Greenwell TJ, et al. The long-term 
results of urethroplasty. J Urol 2003;170:90-2.

2. Brandes SB. Vascular anatomy of the genital skin and the urethra: implications for urethral reconstruction. In: Brandes SB, editor. Urethral reconstructive surgery. Totowa, NJ: Humana Press; 2008. p.153-64.

3. Shenfeld OZ, Kiselgorf D, Gofrit ON, et al. The incidence and causes of erectile dysfunction after pelvic fractures associated with posterior urethral disruption. J Urol 2003;169: 2173-6.

4. Jordan GH, Colen LB. Penile revascularization after pelvic trauma: current rationale and results. Contemp Urol 1997; 19:24-33.

5. Meland NB, Arnold PG, Weiss HC. Management of the recalcitrant total-hip arthroplasty wound. Plast Reconstr Surg 1991;88:681-5.

6. Asaadi M, Murray KA, Russell RC, et al. Experimental evaluation of free-tissue transfer to promote healing of infected wounds in dogs. Ann Plast Surg 1986;17:6-12.

7. Beyer M, Hoffer H, Eggeling T, et al. Free skeletal muscle transplantation to an infarction area: an experimental study in the dog. Microsurgery 1993;14:125-9.

8. Shestak KC, Hendricks DL, Webster MW. Indirect revascularization of the lower extremity by means of microvascular free-muscle flap: a preliminary report. J Vasc Surg 1990;12: 581-5.

9. Tan BK, Chen HC, He TM, et al. Flap prefabrication: the bridge between conventional flaps and tissue-engineered flaps. Ann Acad Med Singapore 2004;33:662-6.

10. Hill MA. Meininger GA. Skeletal muscle microcirculation. In: Barker JH, Anderson GL, Menger MD, editors. Clinically applied micro-circulation research. New York: CRC
Press; 1995. p.297-314.

11. Frank JM. Angiogenesis. In: Barker JH, Anderson GL, Menger MD, editors. Clinically applied micro-circulation research. New York: CRC Press; 1995. p.375-89.

12. Zmora O, Tulchinsky H, Gur E, et al. Gracilis muscle transposition for fistulas between the rectum and urethra or vagina. Dis Colon Rectum 2006;49:1316-21.

13. Lee YT, Lee JM. Gracilis myocutaneous flap for the coverage of an extensive scrotoperineal defect and protection of the ruptured urethra and testes. Yonsei Med J 1990;31:18791.

14. Zinman L. Muscle and myocutaneous grafts in urologic surgery. In: Libertino JA, editor. Pediatric and adult reconstructive urologic surgery. Baltimore: Williams and Wilkins; 1987. p.567-97.

15. Zinman LN. The combined use of fasciocutaneous, muscular and myocutaneous flaps and graft onlays in urethral reconstruction. In: Brandes SB, editor. Urethral reconstructive surgery. Totowa, NJ: Humana Press; 2008. p.171-87.

16. Camp S, Cartwright P, Siddiqi F. The prefabricated gracilis muscle flap with full-thickness skin graft and delay for urethral channel reconstruction. Ann Plast Surg 2011;67:59-61.

17. Beckenstein M, Smith AA, Dinchman K, et al. Muscle flap reconstruction aids in urethral regeneration. Ann Plast Surg 1996;36:641-3.

18. Sharma RK, Biswas G. Repair of a urethral fistula following electrical burns using a gracilis muscle flap. Burns 1990;16: 467-70.

19. Hamlin RH, Nicholson EC. Reconstruction of urethra totally destroyed in labour. Br Med J 1969;2:147-50. 